\title{
Experimental and numerical analysis for optimal design parameters of a falling film evaporator
}

\author{
RAJNEESH KAUSHAL ${ }^{1, *}$, RAJ KUMAR $^{2}$ and GAURAV VATS ${ }^{1,3}$ \\ ${ }^{1}$ Department of Mechanical Engineering, National Institute of Technology, Kurukshetra, Haryana 136119, India \\ ${ }^{2}$ Deenbandhu Chhotu Ram University of Science and Technology, Murthal, Haryana 131039, India \\ ${ }^{3}$ School of Engineering, Indian Institute of Technology, Mandi, Himachal Pradesh 175001, India \\ e-mail: rajneesh@nitkkr.ac.in
}

MS received 29 October 2014; revised 10 September 2015; accepted 6 January 2016

\begin{abstract}
Present study exhibits an experimental examination of mass transfer coefficient and evaporative effectiveness of a falling film evaporator. Further, a statistical replica is extended in order to have optimal controlling parameters viz. non-dimensional enthalpy potential, film Reynolds number of cooling water, Reynolds number of air and relative humidity of up-streaming air. The models not only give an optimal solution but also help in establishing a correlation among controlling parameters. In this context, response surface methodology is employed by aid of design of experiment approach. Later, the response surface curves are studied using ANOVA. Finally, the relations established are confirmed experimentally to validate the models. The relations thus established are beneficent in furtherance of designing evaporators. Additionally, the present study is among the first attempts to reveal the effect of humidity on the performance of falling film evaporator.
\end{abstract}

Keywords. Falling film evaporator; evaporative effectiveness; mass transfer coefficient; ANOVA; response surface methodology.

\section{Introduction}

The concept of evaporative cooling systems have ample spectrum of industrial applications such as refrigeration, power plants, desalinization industries, and petroleum refining as reported by numerous researchers [1-13]. Evaporation of falling film from horizontal copper tubes is a process of heat and mass transfer from liquid to steam. Prime modes of heat transfer are conduction and convection, while mass transfer is influenced by diffusion of molecules [14]. Falling film evaporator is a vital organ of evaporative cooling systems. It is used for heat dissipation from tubes carrying a hot water. Its effectiveness is primarily judged with the help of heat and mass transfer coefficients [15]. Heat and mass transfer coefficients must be high in heat transfer applications, especially in heat pump, refrigeration and air conditioning applications where noteworthy enhancement in cycle efficiency are necessary to be attained by minimizing the temperature difference between the hot fluid and the evaporating fluid [16]. For high evaporative effectiveness, heat and mass transfer coefficients should high. The intrinsic attractions of falling film evaporators are ephemeral time of association between the hot surface of the pipe carrying process fluid and the falling thin film which consequence high heat and mass transfer coefficients, nominal static head

*For correspondence and nominal pressure drop. Simultaneously, ephemeral time of association is a pivot element when working with heat sensitive fluids such as in chemical and food products industries [16]. Therefore, accurate prediction of various parameters associated with the thermal behaviour is a very crucial as well as onerous task. In this direction, the very first attempt was documented by Armbruster and Mitrovic [17]. They carried out an exploratory study on the evaporative cooling of a water film falling on tube banks. Their work revealed that the reduction of water temperature is dependent on air velocity, relative humidity of air and the spacing between tubes in a bank. Later, only a few studies have significantly addressed the issues concerned in this area $[14,18]$. Recently, Kim and Infante Ferreira experimentally investigated the effects of geometry of interacting surface and surfactants on the attributes of Lithium Bromide-water solution falling films [19]. Another attempt is documented by Natale and Nigro [20], they reported a procedure to analogize the local and average heat and mass transfer coefficients with the field of fluid dynamics. Rana et al marked another important attempt in literature and conducted an experimental study of heat and mass transfer on a horizontal single tube of a falling film evaporator and evidenced the correlations of mass transfer coefficient for the design of heat transfer devices [21].

Literature suggests that it is important to note that the dispersal rate of falling fluid in falling film evaporators amounts 
to a millions of litres per minute however the falling fluid requires a supply fluid make-up rate of just 5\% [11]. Thus, it becomes essential to optimize the requirement and performance of a falling film evaporator. This depends on a huge number of factors such as heat transfer area, arrangement of tubes and operating procedure [22-24]. Optimization of these parameters is a reported roadblock $[13,25,26]$. In this context, the present work aims to achieve optimal processing parameters for heat transfer enhancement. This can be done by finding correlations between evaporative effectiveness $(E E)$ and operating variables and also between mass transfer coefficient $(K)$ and operating variables. Evaporative effectiveness is defined as the ratio of heat dissipation rate for evaporating cooling unit to the heat dissipation rate for simple water cooled unit. Concurrently, the operating variables viz. non-dimensional enthalpy potential $(E P)_{\mathrm{dl}}$, film Reynolds number of cooling water $\left(R e_{\mathrm{w}}\right)$ and Reynolds number of air $\left(R e_{\mathrm{a}}\right)$ over an extensive range of relative humidity of up-streaming air $(\phi)$ also play an important role and are therefore essential to be considered. The optimal solution obtained can further be scaled accordingly to the required industrial set-up and will reduce the quantity of water required for the cooling of the process fluid. Parallelly, this will help to have better understanding of the rates of heat and mass transfer, evaporative effectiveness, the mass transfer coefficient and their dependency on various operating variables.

\section{Methods}

As discussed in the previous section, the present study emphasis to enhance $(E E)$ of a falling film evaporator. This is done by first optimizing the operating parameters using response surface methodology (RSM). These include $(E P)_{\mathrm{dl}}$, $R e_{\mathrm{w}}, R e_{\mathrm{a}}$ and $\phi$. Thereafter, the experiments are run and the evaporative effectiveness as well as the mass transfer coefficient is calculated for these optimized parameters.

\subsection{Experimental test rig}

Figure 1 shows a schematic view of the experimental test facility designed for the present study. It consists of eight copper tubes of 23.4 and $25.4 \mathrm{~mm}$ inner and outer diameters, respectively. Each tube is inter-connected with the help of U-shaped copper bend of same wall thickness of 1.0 $\mathrm{mm}$. The effective lengths of the copper tubes used are considered for calculations of heat transfer analysis and the horizontal projection of each copper tube in a row is 600 $\mathrm{mm}$. Thus, the active length $(l)$ of a row of tubes is 4800 $\mathrm{mm}$. The vertical pitch of the tubes in the arrangement is $76.2 \mathrm{~mm}$. Cross-sectional area of the test segment at the test tubes level in air flow direction is $348 \mathrm{~mm}^{2}$. A water spray pipe is installed just above the row of test tubes to fall water droplets exactly over a row of tubes. The inner and outer diameters of the spray pipe are $26.5 \mathrm{~mm}$ and $34 \mathrm{~mm}$,

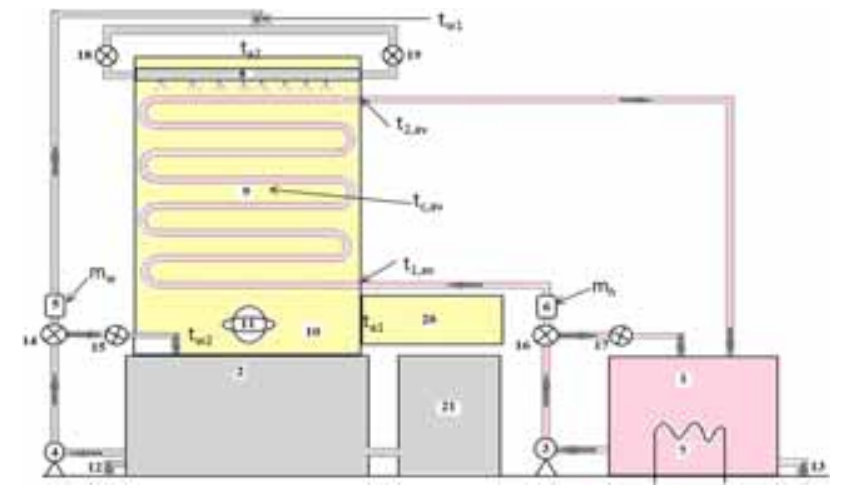

Figure 1. Schematic of test rig.

respectively. The grooves over the spray pipe are cut whose depth is half the thickness of the spray pipe thickness. The pitch of the grooves is $2 \mathrm{~mm}$ and the holes are drilled in each of the grooves. The diameter of each hole is $1.5 \mathrm{~mm}$. Further, the sensors (RTD, PT-100) and a data acquisition system are attached for the thermal measurements. The test rig is also connected to calibrated flow meters and an anemometer to measure the mass flow rates and the velocity of air. Apart from these, a hygro-thermometer and humidifier $(50 \pm 2 \%$ to $90 \pm 2 \%)$ is employed at the inlet to capture the relative humidity of up-streaming air. Table 1 accommodates a brief description of the resolutions and accuracies of instruments used.

\subsection{Experimental procedure}

In case of first type of flow conditions, film Reynolds number of cooling water was varied, keeping the mass flow rate of hot water constant. A steady state was achieved for the observations, temperature of hot water at the inlet and at the outlet of the tubes, temperature of cooling water at the inlet of spray pipe and just below the test unit, average temperature of tube surface, mass flow rates of cooling and hot water were recorded.

For the first, second, third, fourth and fifth set of observations, the above set was repeated for second type of flow conditions. Air velocity at the top of the test section was fixed at $0.8 \mathrm{~m} / \mathrm{s}$. The relative humidity at the inlet of the test section was varied from $50 \pm 2 \%$ to $90 \pm 2 \%$. A steady state was achieved for all the observations, the temperatures and the mass flow rates as stated above in the first type of flow conditions, dry bulb and wet bulb temperatures of air at the inlet of test section, relative humidity of up-streaming air and velocity air at the top of test section were recorded.

The above five sets of experiments were repeated for air velocities at the top of test section at 1.6, 2.4, 3.2 and 4.0 $\mathrm{m} / \mathrm{s}$. All the quantities as stated above were recorded for each observation. The ranges of operating variables are given in table 2 . 
Table 1. Instruments used with their resolutions and accuracies.

\begin{tabular}{lcc}
\hline Sr. no. & Instrument & Resolution and accuracy \\
\hline 1 & RTD sensors (PT-100) & Resolution: $0.1{ }^{\circ} \mathrm{C}$ and $\%$ of error in accuracy: $\pm 1.5 \%$ \\
2 & Flow meters & Resolution: $0.017 \mathrm{~kg} / \mathrm{s}$ and $\%$ of error in accuracy: $\pm 3.0 \%$ \\
3 & Anemometer & Resolution: $0.1 \mathrm{~m} / \mathrm{s}$ and $\%$ of error in accuracy: $\pm 2 \%$ \\
4 & Hygro-thermometer & Resolution: $0.1 \%$ and $\%$ of error in accuracy: $\pm 2 \%$ \\
\hline
\end{tabular}

Table 2. Levels of operating variables chosen for CCD.

\begin{tabular}{lccccc}
\hline Variables & $-2(\alpha)$ & -1 & 0 & +1 & $+2(\alpha)$ \\
\hline Coded levels & & & & & \\
$\operatorname{Re}_{w}$ & 82.00 & 135.75 & 189.50 & 243.25 & 297.00 \\
$\operatorname{Re}_{a}$ & 1245.00 & 2538.00 & 3831.00 & 5124.00 & 6417.00 \\
$(E P)_{d l}$ & 0.02903 & 0.03281 & 0.03659 & 0.04037 & 0.04416 \\
$\phi$ & 50 & 60 & 70 & 80 & 90 \\
\hline
\end{tabular}

\subsection{Governing equations}

The heat dissipation rate from a row of tubes, when both air and cooling water flows simultaneously can be written as

$$
Q_{\mathrm{wa}}=W_{\mathrm{h}} C_{\mathrm{p}}\left(t_{\mathrm{h} 1}-t_{\mathrm{h} 2}\right) .
$$

Reynolds number of air and cooling water are determined as

$$
\begin{gathered}
R e_{\mathrm{a}}=\frac{\rho_{\mathrm{a}} V_{\mathrm{t}} D_{\mathrm{o}}}{\mu_{\mathrm{a}}} \\
\operatorname{Re}_{\mathrm{w}}=\frac{4 \Gamma}{\mu_{\mathrm{w}}} .
\end{gathered}
$$

Liquid film flow rate per unit length of cooling water, $\Gamma$ is given as

$$
\Gamma=\frac{W_{\mathrm{w}}}{2 l},
$$

where $l$ is the active length of a row of tubes and is taken as $4.8 \mathrm{~m}$ and $W_{\mathrm{w}}$ is the mass flow rate of cooling water.Mass transfer coefficient is calculated from

$$
K=\frac{Q_{w a}}{A_{\mathrm{o}}\left(i_{\mathrm{s}, \mathrm{cc}}-i_{\mathrm{a}}\right)},
$$

where $\left(i_{\mathrm{s}, \mathrm{tc}}-i_{\mathrm{a}}\right)$ is the enthalpy potential, the difference of enthalpy of saturated air at the average tube surface temperature and the enthalpy of air at the inlet of evaporator. $A_{\mathrm{o}}$ is the outside surface area of the tube and is calculated as $0.383 \mathrm{~m}^{2}$.

The evaporative effectiveness can be expressed as

$$
E E=\frac{Q_{\mathrm{wa}}}{Q_{\mathrm{w}}}
$$

where $Q_{\mathrm{w}}$ is the heat dissipation rate from a row of tubes, when only cooling water flowing at same operating conditions and is calculated as

$$
Q_{\mathrm{w}}=W_{\mathrm{h}} C_{\mathrm{p}}\left(t_{\mathrm{h} 1}-t_{\mathrm{h} 2}\right) .
$$

\subsection{Response surface methodology (RSM)}

RSM is defined as a gathering of statistical and mathematical methods that are used to evolve, revamp or optimize a product or process [15]. In the present study, a central composite rotatable design (CCRD) is employed to obtain a design matrix using statistical analysis software tool Design Expert 9.0.2. This leads to a regression equation of second order consisting of four variables and two responses. First the responses are fitted to the variables by virtue of multiple regressions. The supremacy to the model fitting is assessed using ANOVA and coefficients of determination. The speculated equation of the quadratic response model is given as [15]

$$
A=B_{0}+\sum B_{i} x_{i}+\sum B_{i i} x_{i}^{2}+\sum B_{i j} x_{i} x_{j}
$$

where ' $A$ ' is response variable computed experimentally. ' $B$ ' is the coefficient of regression of the model, which is having a constant value for a particular model. $x_{i}, x_{j}(i=1$, $5 ; j=1,5)$ designates the independent parameters in terms of coded values. $i, j$ are the linear and quadratic coefficients, respectively. The anticipating capability and certainty of the polynomial model is confirmed by the coefficient of determination $\left(R^{2}\right)$.

\subsection{ANOVA for response surface quadratic model}

Analysis of variance (ANOVA) is a statistical method in which a collection of statistical models used to analyse the differences between group means and their related operations (such as variation among groups) [27-30]. The observed variance in an appropriate variable is apportioned into factors attributable to different causes of deviation using ANOVA. The deviation in a set of observations is divided into distinct components. The point at which the pattern of the curve deviates from one response rate to another is the most favourable point. Consequently, the second-order equation is an exceptional prognosticator of optimized values which 
appears at only a single point. Further in order to analyse the models significance, $F$-test and $p$-test are performed. $F$ ratio is the ratio of "between group's mean square values" to "withingroup mean square values". $p$-values are used to examine the importance of each coefficient which implicates the interaction dominance of each variable. A trivial value of $p$ shows a greater importance of the related coefficient. The Design Expert tool axiomatically examines the results of the $F$-test and $p$-test and determines the probability of all the terms of regression equations. If probability is greater than $F$ for "the proposed model less than 0.005 ", it is significant.

\section{Results and discussion}

As discussed in previous sections, the responses $E E$ and $K$ are primarily effected by $(E P)_{\mathrm{dl}}, R e_{\mathrm{w}}$ and $R e_{\mathrm{a}}$. Therefore, these variables have been studied extensively. However, only a few studies talk about the influence of relative humidity of the air [17]. It has been marked in literature that a variation in $\phi$ can cause an abrupt variation in $E E$ and $K$. Therefore, in the present study we have considered $\phi$ as important variable. Its concentration is varied from 50 to $90 \%$ and corresponding fluctuation in $E E$ and $K$ are measured. Thus the present study has considered the impact of $(E P)_{\mathrm{dl}}, R e_{\mathrm{w}}, R e_{\mathrm{a}}$ and $\phi$ as four important variables to check the performance of falling film evaporator. Initially, we carried out experiments to figure out the range of $R e_{\mathrm{w}}$ by finding out the minimum wetting rate of the tubes. The minimum wetting rate is the minimum mass flow rate of cooling water needed at which the unit length of the tube becomes thoroughly soaked when there is no thermal load. It is important to note, while performing the experiment the hot fluid was flowing through the tube and the cooling water was sprayed from the top. The air was allowed to flow from bottom to top through an air flow controlled duct. Various operating variables thus observed are shown in table 2 .

Later, in order to optimize the pre-decided variables $\left((E P)_{\mathrm{dl}}, R e_{\mathrm{w}}, R e_{\mathrm{a}}\right.$ and $\left.\phi\right)$ a central composite rotatable design (CCRD) matrix is developed with the help of Design Expert software. For given input variables and aforementioned conditions the software suggests carrying out a set of 30 experiments in order to optimize the factors that effect the response. The design matrix hence developed by the coalescence of variables understudy is illustrated in table 3 .

Table 3. CCD design matrix.

\begin{tabular}{|c|c|c|c|c|c|c|c|}
\hline \multirow[b]{2}{*}{ Run no. } & \multirow[b]{2}{*}{ Space type } & \multicolumn{4}{|c|}{ CCD experimental design matrix } & \multirow[b]{2}{*}{$E E$} & \multirow{2}{*}{$\begin{array}{c}K \\
\left(\mathrm{~kg} / \mathrm{m}^{2} \mathrm{~s}\right)\end{array}$} \\
\hline & & $R e_{\mathrm{w}}$ & $R e_{\mathrm{a}}$ & $(E P)_{\mathrm{dl}}$ & $\phi(\%)$ & & \\
\hline 1 & Axial & 178.65 & 3830.74 & 0.03309 & 50 & 1.29 & 0.11991 \\
\hline 2 & Axial & 179.31 & 6378.88 & 0.03198 & 70 & 1.25 & 0.28251 \\
\hline 3 & Factorial & 223.66 & 5128.21 & 0.03072 & 60 & 1.61 & 0.21270 \\
\hline 4 & Axial & 277.12 & 3827.33 & 0.03201 & 70 & 1.51 & 0.18310 \\
\hline 5 & Factorial & 132.29 & 5085.72 & 0.03441 & 60 & 1.25 & 0.16060 \\
\hline 6 & Interior & 181.66 & 3815.42 & 0.03420 & 70 & 1.05 & 0.14622 \\
\hline 7 & Factorial & 134.07 & 5066.17 & 0.03492 & 80 & 0.97 & 0.19813 \\
\hline 8 & Factorial & 229.20 & 2548.90 & 0.03454 & 60 & 1.24 & 0.10210 \\
\hline 9 & Factorial & 132.29 & 5085.72 & 0.03441 & 60 & 1.25 & 0.16060 \\
\hline 10 & Factorial & 228.78 & 5100.08 & 0.03193 & 80 & 1.27 & 0.25180 \\
\hline 11 & Interior & 181.66 & 3815.42 & 0.03420 & 70 & 1.05 & 0.14622 \\
\hline 12 & Factorial & 137.20 & 2514.82 & 0.03954 & 80 & 0.68 & 0.08270 \\
\hline 13 & Axial & 84.70 & 3786.73 & 0.03811 & 70 & 0.84 & 0.10150 \\
\hline 14 & Factorial & 235.83 & 2528.97 & 0.03656 & 80 & 1.02 & 0.11480 \\
\hline 15 & Interior & 181.66 & 3815.42 & 0.03420 & 70 & 1.05 & 0.14622 \\
\hline 16 & Axial & 185.29 & 3793.45 & 0.03563 & 90 & 0.81 & 0.17153 \\
\hline 17 & Factorial & 134.76 & 2528.97 & 0.03828 & 60 & 0.89 & 0.06691 \\
\hline 18 & Factorial & 137.20 & 2514.82 & 0.03954 & 80 & 0.68 & 0.08270 \\
\hline 19 & Interior & 181.66 & 3815.42 & 0.03420 & 70 & 1.05 & 0.14622 \\
\hline 20 & Interior & 181.66 & 3815.42 & 0.03420 & 70 & 1.05 & 0.14622 \\
\hline 21 & Interior & 181.66 & 3815.42 & 0.03420 & 70 & 1.05 & 0.14622 \\
\hline 22 & Factorial & 276.26 & 2553.45 & 0.03333 & 60 & 1.41 & 0.11120 \\
\hline 23 & Factorial & 134.76 & 2528.97 & 0.03828 & 60 & 0.89 & 0.06691 \\
\hline 24 & Factorial & 276.60 & 5105.38 & 0.03103 & 80 & 1.35 & 0.27631 \\
\hline 25 & Axial & 188.66 & 1257.41 & 0.04010 & 70 & 0.66 & 0.05750 \\
\hline 26 & Interior & 181.66 & 3815.42 & 0.03420 & 70 & 1.05 & 0.14622 \\
\hline 27 & Factorial & 268.02 & 5145.05 & 0.02919 & 60 & 1.64 & 0.24511 \\
\hline 28 & Interior & 181.66 & 3815.42 & 0.03420 & 70 & 1.05 & 0.14622 \\
\hline 29 & Factorial & 235.83 & 2528.97 & 0.03656 & 80 & 1.02 & 0.11480 \\
\hline 30 & Factorial & 134.07 & 5066.17 & 0.03492 & 80 & 0.97 & 0.19813 \\
\hline
\end{tabular}




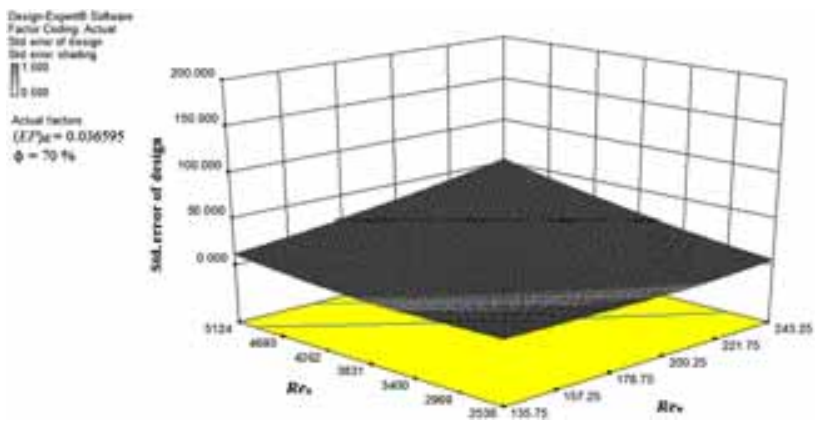

Figure 2. 3D surface plot of standard error of design.

The standard error of design for the selected ranges of operating variables $\left(E P_{\mathrm{dl}}, R e_{\mathrm{w}}, R e_{\mathrm{a}}\right.$ and $\left.\phi\right)$ and responses $(E E$ and $K$ ) is graphically captured in figure 2 .

Further, the effect of operating variables on responses is optimized using RSM. Based on the computed responses by using experimental data, multiple regression analysis carried out by the software has given the following polynomial equations in terms of actual factors

$$
\begin{aligned}
E E= & -278.38788+0.40130 \times R e_{\mathrm{w}}+0.021705 \times R e_{\mathrm{a}} \\
& +13030.61705 \times(E P)_{\mathrm{dl}}-0.76869 \times \phi \\
& -1.54321 \times 10^{-5} \times R e_{\mathrm{w}} \times R e_{\mathrm{a}}-9.26943 \times R e_{\mathrm{w}} \\
& \times(E P)_{\mathrm{dl}}+5.44680 \times 10^{-4} \times R e_{\mathrm{w}} \times \phi-0.49988 \\
& \times R e_{\mathrm{a}} \times(E P)_{\mathrm{dl}}+2.80149 \times 10^{-5} \times R e_{\mathrm{a}} \times \phi \\
& +18.35699 \times(E P)_{\mathrm{dl}} \times \phi-1.43130 \times 10^{-4} \times R e_{\mathrm{w}}^{2} \\
& -4.20081 \times 10^{-7} \times R e_{\mathrm{a}}^{2}-1.52857 \times 10^{5} \\
& \times(E P)_{\mathrm{dl}}^{2}-6.79114 \times 10^{-4} \times \phi^{2}
\end{aligned}
$$

$$
\begin{aligned}
K= & +3.54267-2.88705 \times 10^{-3} \times R e_{\mathrm{w}}-2.6193 \times 10^{-4} \\
& \times R e_{\mathrm{a}}-156.1333 \times(E P)_{\mathrm{dl}}+4.1818 \times 10^{-3} \times \phi \\
& +1.47043 \times 10^{-7} \times R e_{\mathrm{w}} \times R e_{\mathrm{a}}+0.053342 \times R e_{\mathrm{w}} \\
& \times(E P)_{\mathrm{dl}}+4.38379 \times 10^{-6} \times R e_{\mathrm{w}} \times \phi+4.99420 \\
& \times 10^{-3} \times R e_{\mathrm{a}} \times(E P)_{\mathrm{dl}}+1.62683 \times 10^{-7} \times R e_{\mathrm{a}} \\
& \times \phi-0.11575 \times(E P)_{\mathrm{dl}} \times \phi+6.17068 \times 10^{-7} \\
& \times R e_{\mathrm{w}}^{2}+1.00364 \times 10^{-8} \times R e_{\mathrm{a}}^{2}+1781.06880 \\
& \times(E P)_{\mathrm{dl}}^{2}+3.61592 \times 10^{-6} \times \phi^{2},
\end{aligned}
$$

For choosing any value of evaporative effectiveness lying in the range of 0.66 to 1.64 (table 3 ) and corresponding values of Reynolds numbers of air and water, one may directly find the value of dimensionless enthalpy potential from the correlation of evaporative effectiveness. The corresponding mass transfer coefficient may easily be find out by using

\begin{tabular}{|c|c|c|c|c|c|}
\hline Source & Sum of squares & DF & Mean square & F-value $^{a}$ & Prob. $>\mathrm{F}$ (p-value) \\
\hline Model & 1.88 & 14 & 0.13 & 271.85 & $<0.0001$ Significant \\
\hline$R e_{w}$ & $3.408 \times 10^{-3}$ & 1 & $3.408 \times 10^{-3}$ & 6.92 & 0.0189 \\
\hline$R e_{a}$ & $4.271 \times 10^{-3}$ & 1 & $4.271 \times 10^{-3}$ & 8.67 & 0.0101 \\
\hline$(E P)_{d l}$ & $5.538 \times 10^{-3}$ & 1 & $5.538 \times 10^{-3}$ & 11.24 & 0.0044 \\
\hline$\phi$ & $1.529 \times 10^{-3}$ & 1 & $1.529 \times 10^{-3}$ & 3.10 & 0.0985 \\
\hline$R e_{\mathrm{w}} \times R e_{\mathrm{a}}$ & 0.012 & 1 & 0.012 & 24.41 & 0.0002 \\
\hline$R e_{\mathrm{w}} \times(E P)_{d l}$ & 0.011 & 1 & 0.011 & 22.46 & 0.0003 \\
\hline $\operatorname{Re}_{w} \times \phi$ & $5.991 \times 10^{-3}$ & 1 & $5.991 \times 10^{-3}$ & 12.16 & 0.0033 \\
\hline$R e_{a} \times(E P)_{d l}$ & 0.011 & 1 & 0.011 & 22.87 & 0.0002 \\
\hline$R e_{a} \times \phi$ & 0.010 & 1 & 0.010 & 21.27 & 0.0003 \\
\hline$(E P)_{d l} \times \phi$ & $9.765 \times 10^{-3}$ & 1 & $9.765 \times 10^{-3}$ & 19.81 & 0.0005 \\
\hline$R e_{w}^{2}$ & 0.011 & 1 & 0.011 & 21.60 & 0.0003 \\
\hline$R e_{a}^{w}$ & 0.017 & 1 & 0.017 & 35.49 & $<0.0001$ \\
\hline$(E P)_{d l}^{2}$ & 0.010 & 1 & 0.010 & 21.11 & 0.0004 \\
\hline$\phi^{2}$ & $8.144 \times 10^{-3}$ & 1 & $8.144 \times 10^{-3}$ & 16.53 & 0.0010 \\
\hline Residual & $7.392 \times 10^{-3}$ & 15 & $4.928 \times 10^{-4}$ & & \\
\hline Lack of fit & $7.392 \times 10^{-3}$ & 3 & $2.464 \times 10^{-3}$ & & \\
\hline
\end{tabular}
graphical representation or correlation of mass transfer coefficient. Then the suitable outside surface area of the heat exchanger tubes can be determined using Eq. (3). Keeping in mind the space constraint, one can determine the diameter of tube and length of tube (no. of tubes) for a particular evaporative heat exchanger. Such design of the evaporative heat exchanger would be optimal and would yield energy save.

Equations (9) and (10) indicate that $E E$ and $K$ have a compounded amalgamation with autonomous variables which involves first and second order polynomials and can have abounding maxima points. Also, Eqs. (9) and (10) suggest that the reverting models are essentially quadratic; thence the models are good prognosticators of optimum conditions. The variables that effect $E E$ and $K$ within the

Table 4. ANOVA for response surface quadratic model of evaporative effectiveness.

The Model $F$-value of 271.85 implies the model is significant.

${ }^{\text {a }} \mathrm{F}$-test measures the significance of the model. 
Table 5. ANOVA for response surface quadratic model of mass transfer coefficient.

\begin{tabular}{|c|c|c|c|c|c|}
\hline Source & Sum of squares & $\mathrm{DF}$ & Mean square & F-value $^{a}$ & Prob. $>$ F (p-value) \\
\hline Model & 0.10 & 14 & $7.449 \times 10^{-3}$ & 5584.05 & $<0.0001$ Significant \\
\hline$R e_{w}$ & $5.630 \times 10^{-7}$ & 1 & $5.630 \times 10^{-7}$ & 0.42 & 0.5257 \\
\hline$R e_{a}$ & $9.847 \times 10^{-6}$ & 1 & $9.847 \times 10^{-6}$ & 7.38 & 0.0159 \\
\hline$(E P)_{d l}$ & $4.031 \times 10^{-7}$ & 1 & $4.031 \times 10^{-7}$ & 0.30 & 0.5906 \\
\hline$\phi$ & $1.615 \times 10^{-5}$ & 1 & $1.615 \times 10^{-5}$ & 12.10 & 0.0034 \\
\hline$R e_{w} \times R e_{a}$ & $1.092 \times 10^{-6}$ & 1 & $1.092 \times 10^{-6}$ & 0.82 & 0.3798 \\
\hline$R e_{w} \times(E P)_{d l}$ & $3.666 \times 10^{-7}$ & 1 & $3.666 \times 10^{-7}$ & 0.27 & 0.6078 \\
\hline$R e_{w} \times \phi$ & $3.881 \times 10^{-7}$ & 1 & $3.881 \times 10^{-7}$ & 0.29 & 0.5975 \\
\hline$R e_{a} \times(E P)_{d l}$ & $1.125 \times 10^{-6}$ & 1 & $1.125 \times 10^{-6}$ & 0.84 & 0.3729 \\
\hline$R e_{a} \times \phi$ & $3.535 \times 10^{-7}$ & 1 & $3.535 \times 10^{-7}$ & 0.26 & 0.6142 \\
\hline$(E P)_{d l} \times \phi$ & $3.882 \times 10^{-7}$ & 1 & $3.882 \times 10^{-7}$ & 0.29 & 0.5975 \\
\hline$R e_{w}^{2}$ & $1.979 \times 10^{-7}$ & 1 & $1.979 \times 10^{-7}$ & 0.15 & 0.7055 \\
\hline$R e_{a}^{2}$ & $9.983 \times 10^{-6}$ & 1 & $9.983 \times 10^{-6}$ & 7.48 & 0.0153 \\
\hline$(E P)_{d l}^{2}$ & $1.412 \times 10^{-6}$ & 1 & $1.412 \times 10^{-6}$ & 1.06 & 0.3198 \\
\hline$\phi^{2}$ & $2.309 \times 10^{-7}$ & 1 & $2.309 \times 10^{-7}$ & 0.17 & 0.6833 \\
\hline Residual & $2.001 \times 10^{-5}$ & 15 & $1.334 \times 10^{-6}$ & & \\
\hline Lack of fit & $2.001 \times 10^{-5}$ & 3 & $6.671 \times 10^{-6}$ & & \\
\hline
\end{tabular}

The Model $F$-value of 5584.05 implies the model is significant.

${ }^{a} F$-test measures the significance of the model.


Figure 3. Normal plots of residuals for (a) evaporative effectiveness and (b) mass transfer coefficient.

experimental space understudy produce the surface plots of the regression equations. The plots thus obtained are observed using ANOVA; and $F$ and $p$-values are calculated,

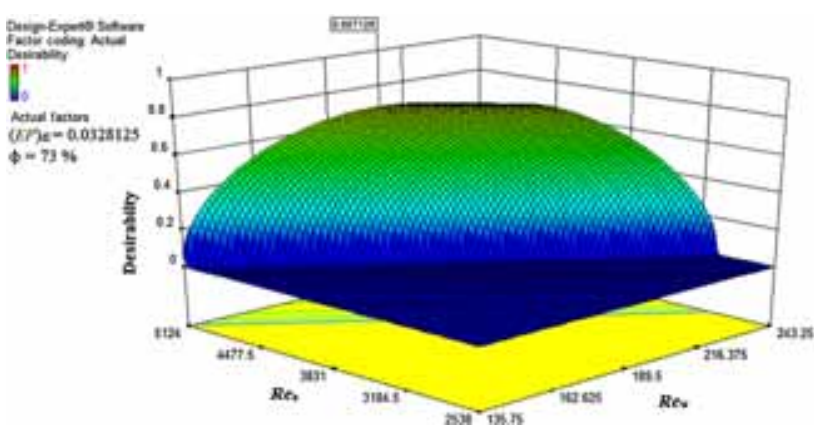

Figure 4. Desirability plot of numerical solution.

which verifies the robustness of the results. A $F$-value of 271.85 for $E E, 5584.05$ for $K$ and $p$-value of less than 0.0001 for both are noticed and are indicated in tables (4 and 5). Tables 4 and 5 suggest that $(E P)_{\mathrm{dl}}$ has the apical effect on $E E$ whereas comparatively $(E P)_{\mathrm{dl}} \times \phi$ has considerable effects on $E E$ in comparison to $R e_{\mathrm{w}}$ and $R e_{\mathrm{a}}$. Rest of the values are found to be insignificant in the proposed equation. Contemporarily, $(E P)_{\mathrm{dl}}^{2}$ is found to have the apical effect on $K$ and ' $R e_{\mathrm{w}} \times(E P)_{\mathrm{dl}}$ ' is found to have a minute effect. Typical plots of residuals for $E E$ and $K$, representing the studentized residuals with normal percent probability as shown in figure 3 . The plot of desirability for the first numerical solution nominated by the software, for the entire ranges of $R e_{\mathrm{w}}$ and $R e_{\mathrm{a}}$ is exhibited in figure 4, keeping two variables constant such as non-dimensional enthalpy potential $(0.0327472)$ and relative humidity $(73 \%)$. 



Figure 5. 3D surface plots of different operating variables and evaporative effectiveness.

The plotted models for $E E$ and $K$ are shown in figures 5 and 6. $E E$ changes with alteration in $R e_{\mathrm{w}}$ and $R e_{\mathrm{a}}$ as depicted in figure 5(a), with constant non-dimensional enthalpy potential $(0.036595)$ and relative humidity of upstreaming air (70\%). Also, it is noted that $E E$ changes with variation in $R e_{\mathrm{w}}$ and $(E P)_{\mathrm{dl}}$, while variables $R e_{\mathrm{a}}(3831.00)$ and $\phi(70 \%)$ are kept constant as displayed in figure 5(b). The maximum value of $E E(1.302)$ is achieved at $R e_{\mathrm{a}}$ $(3831.00) ;(E P)_{\mathrm{dl}}(0.036595)$, with the increment in $\phi$ as revealed in figure 5(c). The maximum value of $E E$ (1.302) is also revealed in figure 5(d) at $R e_{\mathrm{w}}(189.50) ; \phi(70 \%)$. Figure 5(e) depicts that the highest value of $E E$ at $R e_{\mathrm{w}}$ $(189.50)$ and $(E P)_{\mathrm{dl}}(0.036595)$. Figure 5(f) suggests that for $R e_{\mathrm{w}}(189.50)$ and $R e_{\mathrm{a}}(3831.00)$, the maximum value of $E E$ is achieved. In a similar fashion, the variations of $K$ with $(E P)_{\mathrm{dl}}, R e_{\mathrm{w}}$ and $R e_{\mathrm{a}}$ are exhibited in figures 6(a) to $6(f)$. The optimum conditions obtained by aid of numerical optimization using Design expert (Stat Ease) are shown in table 6. The experiments were run accordingly and the distinctive operating conditions corresponding to the optimum values for maximum $E E$ and $K$ are as follows- $R e_{\mathrm{w}}$ : 204.96, $R e_{\mathrm{a}}: 5123.98,(E P)_{\mathrm{d} 1}: 0.033$ and $\phi: 73 \%$. The predicted $E E$ and $K$ obtained from the optimization are 1.302 and $0.220 \mathrm{~kg} / \mathrm{m}^{2} \mathrm{~s}$, respectively. The desirability: 0.687 is achieved for at least 17 numerical solutions (only first 10 solutions are shown in table 6). The first numerical solution is selected since the $E E$ and $K$ has optimum values with maximum desirability.

Finally, experiments were conducted to establish the accuracy of the models. The parameters optimized using the proposed models were contemplated in the experimental set-up and $E E$ and $K$ are calculated. The similar procedure is repeated twice to confirm the consistency (table 7). The values predicted by using correlation 

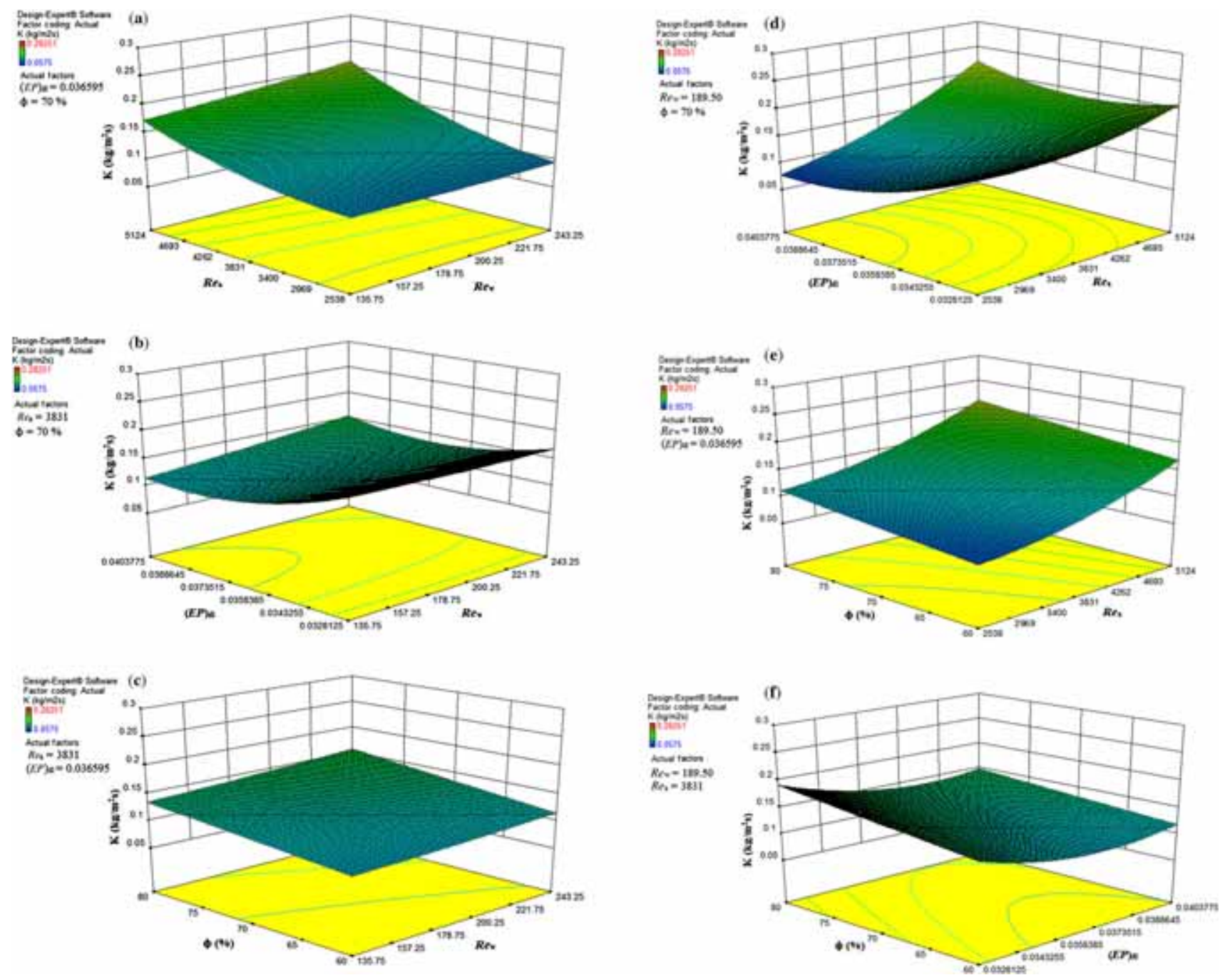

Figure 6. 3D surface plots of different operating variables and mass transfer coefficient.

Table 6. Numerical optimisation of the parameters using RSM.

\begin{tabular}{lccccccc}
\hline Solution no. & $R e_{\mathrm{w}}$ & $R e_{\mathrm{a}}$ & $(E P)_{\mathrm{dl}}$ & $\phi$ & $E E$ & \multicolumn{2}{c}{$\begin{array}{c}\mathrm{C}^{2} \\
\left(\mathrm{~kg} / \mathrm{m}^{2} \mathrm{~s}\right)\end{array}$} \\
\hline 1 & 204.96 & 5123.98 & 0.033 & 73 & 1.302 & 0.220 & 0.687 Selected \\
2 & 204.98 & 5123.99 & 0.033 & 73 & 1.301 & 0.220 & 0.687 \\
3 & 205.68 & 5123.99 & 0.033 & 73 & 1.298 & 0.221 & 0.687 \\
4 & 203.87 & 5123.99 & 0.033 & 72 & 1.308 & 0.218 & 0.687 \\
5 & 206.03 & 5123.97 & 0.033 & 73 & 1.297 & 0.221 & 0.687 \\
6 & 203.73 & 5123.99 & 0.033 & 72 & 1.305 & 0.219 & 0.687 \\
7 & 204.70 & 5122.48 & 0.033 & 73 & 1.304 & 0.219 & 0.687 \\
8 & 203.33 & 5123.98 & 0.033 & 72 & 1.307 & 0.218 & 0.687 \\
9 & 203.65 & 5123.99 & 0.033 & 72 & 1.311 & 0.217 & 0.687 \\
10 & 201.80 & 5123.92 & 0.033 & 71 & 1.318 & 0.216 & 0.687 \\
\hline
\end{tabular}

derived (Eqs. 2 and 3) of $E E(1.275)$ and $K(0.217 \mathrm{~kg} /$ $\mathrm{m}^{2} \mathrm{~s}$ ) are in close approximation with the experimental average values. In addition, extra experiments have been performed for the range of values close to the optimized values and are documented in table 7. Additionally, it has been noticed that $E E$ varies from 1.156 to 1.560 and $K$ varies from $0.205 \mathrm{~kg} / \mathrm{m}^{2}$ s to $0.264 \mathrm{~kg} / \mathrm{m}^{2} \mathrm{~s}$. Moreover, it is found that the $E E$ does not change significantly with 
Table 7. Validation of experiments for the optimum conditions.

\begin{tabular}{|c|c|c|c|c|c|c|}
\hline Exp. no. & $R e_{\mathrm{w}}$ & $R e_{\mathrm{a}}$ & $(E P)_{\mathrm{dl}}$ & $\phi$ & $E E$ & $\begin{array}{c}K \\
\left(\mathrm{~kg} / \mathrm{m}^{2} \mathrm{~s}\right)\end{array}$ \\
\hline \multicolumn{7}{|c|}{ Optimum conditions } \\
\hline 1 & 205.05 & 5125.50 & 0.033 & 73 & 1.389 & 0.232 \\
\hline 2 & 205.05 & 5125.50 & 0.033 & 73 & 1.387 & 0.231 \\
\hline \multicolumn{7}{|c|}{ Around optimum conditions } \\
\hline 3 & 200.50 & 5120.80 & 0.033 & 70 & 1.290 & 0.228 \\
\hline 4 & 195.00 & 5121.90 & 0.032 & 72 & 1.275 & 0.222 \\
\hline 5 & 190.10 & 5118.55 & 0.032 & 72 & 1.266 & 0.219 \\
\hline 6 & 190.00 & 5115.05 & 0.032 & 75 & 1.156 & 0.205 \\
\hline 7 & 210.70 & 5122.09 & 0.033 & 72 & 1.390 & 0.230 \\
\hline 8 & 219.50 & 5122.15 & 0.033 & 71 & 1.395 & 0.232 \\
\hline 9 & 225.80 & 5130.25 & 0.034 & 70 & 1.405 & 0.239 \\
\hline 10 & 235.55 & 5132.00 & 0.034 & 68 & 1.560 & 0.264 \\
\hline
\end{tabular}
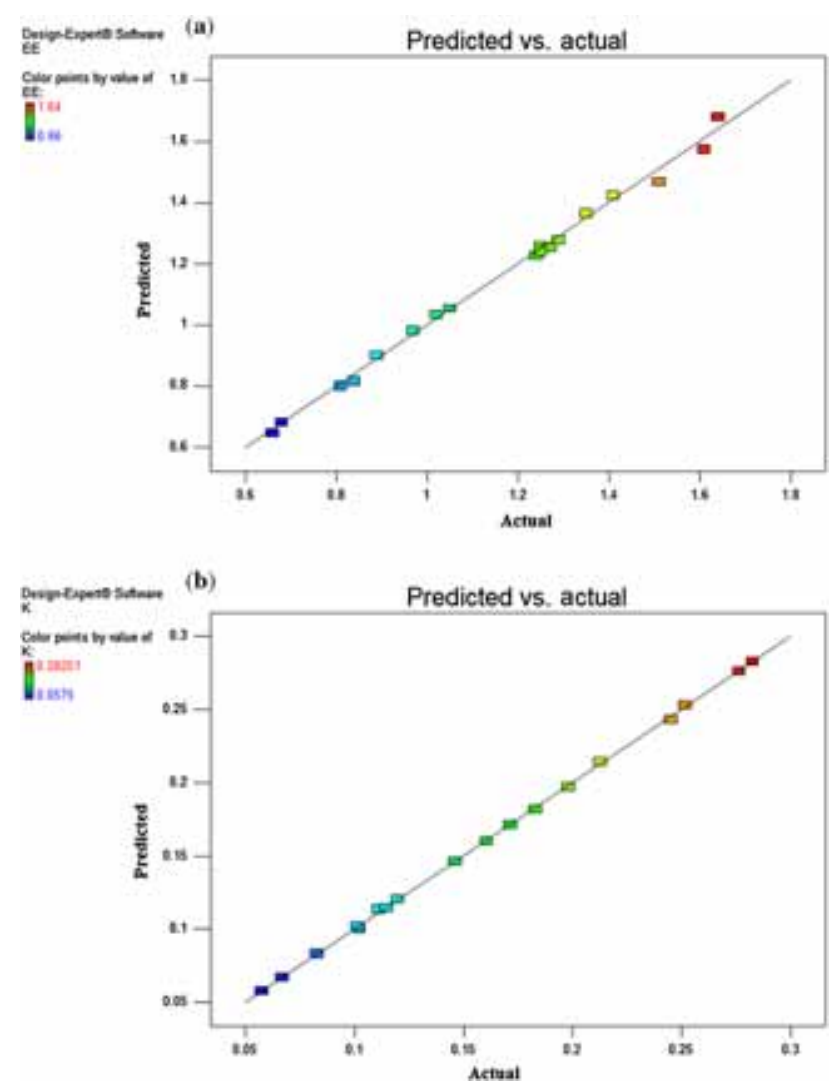

Figure 7. Predicted vs actual plots for (a) evaporative effectiveness and (b) mass transfer coefficient.

$R e_{\mathrm{a}}$ over a given set of $R e_{\mathrm{w}}$ and $\phi$. At specified values (table 6) of $R e_{\mathrm{w}}$ and $R e_{\mathrm{a}}$, the maximum values of the $K$ are achieved with the increase in $\phi$. It is comprehended from the correlations derived that $K$ increases with $R e_{\mathrm{w}}$ and with $R e_{\mathrm{a}}$. However, the increase in $K$ with $R e_{\mathrm{w}}$ is more pronounced than those of $R e_{\mathrm{a}}$. The maximum value of $E E$ can be ascertained from the graphical results for a given set of operating conditions. Hence the systems of like configurations (a row of tubes in a vertical plane) operated under similar conditions may get maximum $E E$ for energy conservation. Figure 7 recapitulates the finding of experimental and predicted values of both $E E$ and $K$. Therefore, it is concluded from the results that the optimization methodology used is very effective and serve in an appropriate manner leading to save ample time in reckoning the design parameters. Also, the present study is among the first attempts to illustrate the effect of humidity of air on $E E$ and $K$.

\section{Conclusion}

The maximum values of $E E$ and $K$ are depicted to be 1.389 and $0.2320 \mathrm{~kg} / \mathrm{m}^{2} \mathrm{~s}$, respectively. It is clear from the results that the $E E$ does not change significantly with $R e_{\mathrm{a}}(1245.00$ to 6417.00) over a given set of $R e_{\mathrm{w}}$ (82.00 to 297.00). Secondly, correlations for $E E$ and $K$ with distinct operating variables were established over an extensive range of operating conditions that would save an appreciable time in reckoning the design parameters. Also, these will serve effectively to predict the performance of falling film evaporators of similar arrangement. Finally, we conclude that the experimental design approach is an expedient tool to understand the interaction among operating parameters and their effect on $E E$ and $K$.

\section{Acknowledgment}

The authors gratefully acknowledge the infrastructure and test facility provided by the National Institute of Technology, Kurukshetra, India.

\section{Nomenclature}

$E E$ evaporative effectiveness

$E P$ enthalpy potential

$K$ mass transfer coefficient, $\mathrm{kg} / \mathrm{m}^{2} \mathrm{~s}$

$\mathrm{m}$ mass flow rate, $\mathrm{kg} / \mathrm{s}$

Re Reynolds number

$\mathrm{t}$ temperature, ${ }^{\circ} \mathrm{C}$

\section{Greek symbols}

$\phi \quad$ relative humidity, $\%$

\section{Subscripts}

a air

av average 
c tube surface

dl non-dimensional

h hot water

w cooling water

1 inlet

2 outlet

\section{References}

[1] Abraham R and Mani A 2014 Experimental studies on thermal spray-coated horizontal tubes for falling film evaporation in multi-effect desalination system. Desalination Water Treatment (ahead-of-print): 1-12

[2] Bustamante J G 2014 Falling-film evaporation over horizontal rectangular tubes

[3] Christians M and Thome J R 2012 Falling film evaporation on enhanced tubes, part 1: Experimental results for pool boiling, onset-of-dryout and falling film evaporation. Int. J. Refrigeration 35(2): 300-312

[4] Chyu M-C and Bergles A 1987 An analytical and experimental study of falling-film evaporation on a horizontal tube. J. Heat Transfer 109(4): 983-990

[5] Fernández-Seara J and Pardiñas Á Á 2014 Refrigerant falling film evaporation review: Description, fluid dynamics and heat transfer. Appl. Therm. Eng. 64(1): 155-171

[6] Gonda A, Lancereau P et al 2014 Water falling film evaporation on a corrugated plate. Int. J. Therm. Sci. 81: 29-37

[7] Gong L, Shen S et al 2015 Three-dimensional heat transfer coefficient distributions in a large horizontal-tube falling film evaporator. Desalination 357: 104-116

[8] Monnier H, Portha J-F et al 2012 Intensification of heat transfer during evaporation of a falling liquid film in vertical microchannels-Experimental investigations. Chem. Eng. Sci. 75: 152-166

[9] Ribatski G and Jacobi A M 2005 Falling-film evaporation on horizontal tubes-A critical review. Int. J. Refrigeration 28(5): 635-653

[10] Sharma S, Rangaiah G et al 2012. Multi-objective optimization using MS Excel with an application to design of a falling-film evaporator system. Food Bioproducts Process. 90(2): 123-134

[11] van Rooyen E and Thome J 2014 Flow boiling data and prediction method for enhanced boiling tubes and tube bundles with R-134a and R-236fa including a comparison with falling film evaporation. Int. J. Refrigeration 41: 60-71

[12] Yang L, Xu Z et al 2014 Characterization of the microscopic mechanics in falling film evaporation outside a horizontal tube. Desalination Water Treatment (ahead-of-print): 1-6.
[13] Zeng X, Quek C X et al 2014 Falling film evaporation characteristics of microalgae suspension for biofuel production. Appl. Therm. Eng. 62(2): 341-350

[14] Yang L and Shen S 2008. Experimental study of falling film evaporation heat transfer outside horizontal tubes. Desalination 220(1): 654-660

[15] Myers R H, Montgomery D C et al 2009 Response surface methodology: process and product optimization using designed experiments, John Wiley \& Sons

[16] Alhusseini A A, Tuzla K et al 1998 Falling film evaporation of single component liquids. Int. J. Heat Mass Transfer 41(12): 1623-1632

[17] Armbruster R and Mitrovic J 1998 Evaporative cooling of a falling water film on horizontal tubes. Exp. Thermal Fluid Sci. 18(3): 183-194

[18] Weiland P S 1994 National Environmental Policy Act of 1969. U.S.C. 42: 102-105

[19] Kim D and Infante Ferreira C 2009 Flow patterns and heat and mass transfer coefficients of low Reynolds number falling film flows on vertical plates: Effects of a wire screen and an additive. Int. J. Refrigeration 32(1): 138-149

[20] Di Natale F and R Nigro 2012 A critical comparison between local heat and mass transfer coefficients of horizontal cylinders immersed in bubbling fluidised beds. Int. J. Heat Mass Transfer 55(25): 8178-8183

[21] Rana R, Charan V et al 1986 Heat and mass transfer from a horizontal tube of an evaporative heat dissipator. Int. J. Heat Mass Transfer 29(4): 555-562

[22] Prost J, González M et al 2006 Determination and correlation of heat transfer coefficients in a falling film evaporator. $J$. Food Eng. 73(4): 320-326

[23] Webb R L 1981 The evolution of enhanced surface geometries for nucleate boiling. Heat Transfer Eng. 2(3-4): 46-69

[24] Webb R L and Kim N-H 1994 Principl of enhanced heat transfer, New York, Wiley

[25] Habert M 2009 Falling film evaporation on a tube bundle with plain and enhanced tubes.

[26] Kumar R 2014 Enhancement in evaporative effectiveness of an evaporative tubular heat dissipator using experimental design approach. Heat Transfer-Asian Research

[27] Baldeaux J and Gnewuch M 2014 Optimal randomized multilevel algorithms for infinite-dimensional integration on function spaces with ANOVA-type decomposition. SIAM J. Numer. Anal. 52(3): 1128-1155

[28] Cardinal R N and Aitken M R 2013 ANOVA for the behavioral sciences researcher, Psychology Press

[29] Gu C 2013 Smoothing spline ANOVA models, Springer

[30] Kang E L and Cressie N 2013 Bayesian hierarchical ANOVA of regional climate-change projections from NARCCAP Phase II. Int. J. Appl. Earth Observation Geoinformation 22: 3-15 